\title{
MTAS: WHERE ARE WE NOW?
}

\section{Colleen Shannon takes a detailed snapshot of where trainees currently stand}

\section{What's the problem?}

Each year thousands of junior doctors compete fiercely for training posts in the NHS These posts lead eventually to the coveted title of consultant, and the route has never been an easy one. However, junior doctors say that recent reforms of the selection and training system have made this one of the worst years ever.

There are three parts to the problem. Firstly, a new, centralised selection process is being introduced. It has been plagued with problems, and as a result the shortlisting

\section{A primer: MMC and MTAS}

The NHS Plan, published in 2000, promised to modernise the senior house officer (SHO) grade, which was seen to lack clear educational and career pathways. Trainees had to move to new posts frequently, as often as every six months. The total amount of time that doctors spent at SHO level varied hugely.

Modernising Medical Careers (MMC) was launched in 2003 to make training more efficient and consistent. It is a UK-wide policy, with separate implementation in each of the four nations. MMC aims to provide structured, competency based postgraduate medical training. Although MMC is the training scheme, the medical training application service (MTAS) is the national recruitment portal. MTAS was developed with an external supplier, Methods Consulting, which had already set up the NHS jobs recruitment service.

For foundation programmes MTAS was launched in October 2006, handling about 6000 applications. For specialty recruitment the service went live in January 2007, and more than 30000 applications were received.

Under the old system junior doctors applied for jobs locally by sending traditional CVs or application forms. They applied for many jobs, at different times of the year, according to local schedules. Under MTAS junior doctors complete one online application, and everyone in the UK applies at the same time. Doctors can apply for a maximum of four training posts. They must rank these in order of preference.

Critics of MTAS say that the application form is too simple and poorly designed and that this is one of the main reasons the shortlisting process did not work. process for the latest recruitment round has collapsed. There have been claims that the medical training application system (MTAS, see box) failed to pick up all the best candidates and that many excellent doctors were not shortlisted for interview. Also, junior doctors were required to apply online, but the MTAS website suffered technical problems at a critical time in the process. The process is now behind schedule, and because posts must be filled by August the deadlines are short.

Secondly, the number of applicants far exceeds the number of training posts that will be available. This situation is related to the underlying system of workforce planning. Thirdly, in the background is a radical change to training (as a result of the NHS's new Modernising Medical Careers (MMC) strategy-see box), which is new territory for juniors and their mentors alike. Training periods will be shorter, and the career path is more rigid than before. However, it should mean that more junior doctors will progress to be consultants earlier on in their careers.

\section{What's the latest news?}

On Monday health secretary Patricia Hewitt announced a review of the government's MMC programme (see News, p 818).

Earlier this month two dozen consultants wrote to the Times saying that the entire selection process should be abandoned immediately. Two of the government's senior medical advisers for the new schemes have resigned. And the application process is being changed midstream. Now a review group has decided that, in the interests of fairness, additional interviews should be offered. Therefore in England everyone will now get an interview for the post they listed as their first choice. Applicants in Scotland, Wales, and Northern Ireland will also be offered additional interviews. Doctors who were not shortlisted initially will welcome the decision, but it may be less popular with those who were already doing well under the new procedures.

A junior doctors' protest group, Remedy UK, thinks that the about-face on interviews represents a breach of employment laws. The organisation said this week that the government's MMC review would not affect the legal action it was planning.
How many training posts are up for grabs? It depends on the source of the figures and how you look at them. Last week the Department of Health told the BMJ that about 20000 training posts are on offer in the UK. Previously, the department had said that up to 23000 posts were available. However, this figure included $3000 \mathrm{GP}$ trainees, who did not have to apply through the same MTAS procedure.

Another point to consider is that the fixed term specialist training appointment (FTSTA) posts account for about $20 \%$ of all training posts in England (fig). These junior hospital jobs carry a maximum one year contract and are a diversion from the main training route for consultants and GP principals. Trainees accepting FTSTA posts may find it difficult to get back in the race.

The BMA has criticised the "misleading" way these figures were initially presented. The BMA has calculated that in reality about 18500 jobs are on offer. This figure was obtained by simply adding up the available training posts listed in competition tables on the MTAS website.

\section{How many applicants are competing?}

The latest figures from the health department indicate that about 34500 applications were submitted. The department told the BMJ that it has not analysed the characteristics of the applicant pool in any detail.

Tables on the MTAS website do show how many doctors are chasing each post, and the data are broken down into region, training year and specialty (table).

\section{How should junior doctors proceed with} their applications?

Junior doctors would be wise to seek advice from their clinical tutors. The BMA is also preparing a guide, which is due out in May.

The following guidance published by NHS Employers applies to clinical posts in England (the selection process for academic medicine is still being finalised)-some of the details are different in Scotland, Wales, and Northern Ireland:

- Interviews already offered will be honoured and the outcome will still count

- Doctors who have already had an 


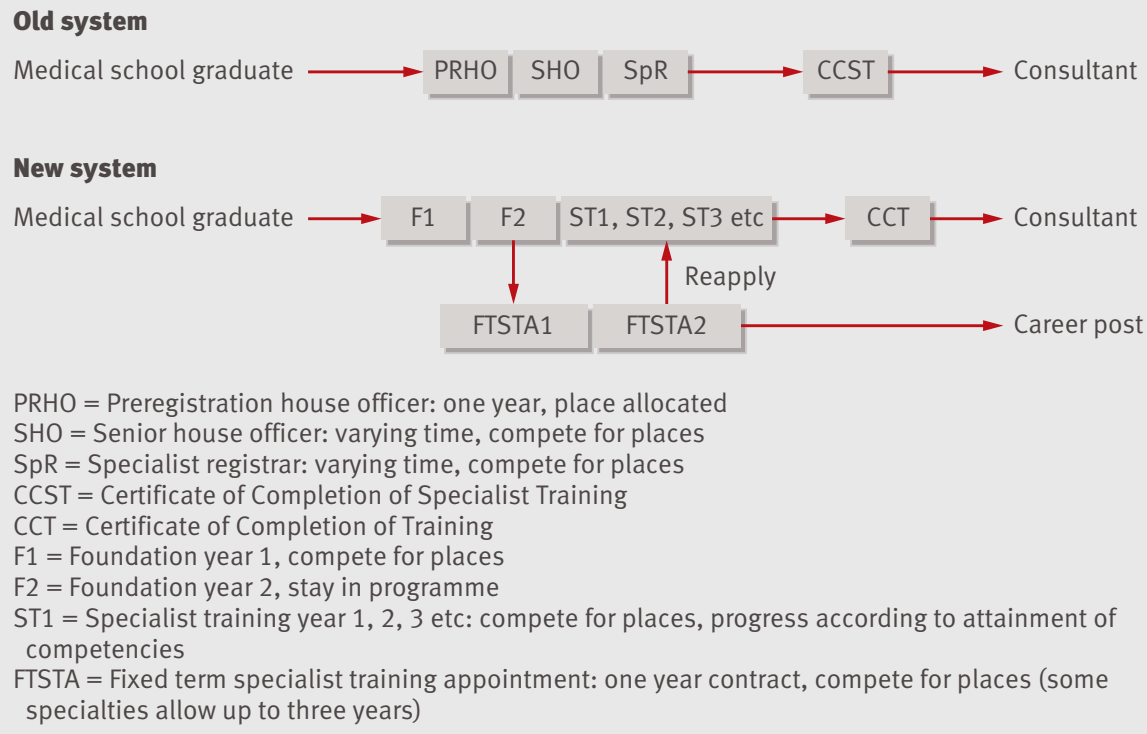

ST1 $=$ Specialist training year 1, 2, 3 etc: compete for places, progress according to attainment of competencies

FTSTA = Fixed term specialist training appointment: one year contract, compete for places (some specialties allow up to three years)

interview can just let the process continue or can change their first choice to get another interview

- Doctors who have not been offered an interview yet will now get one for their first choice of post. They can change their first choice if they think this will be advantageous

- In general practice the process will continue according to the original plans but to a longer timetable.

\section{How does the timetable look?}

Very tight. The dates are constantly changing, and junior doctors will have to watch the MTAS and MMC websites. A timetable is also posted on the NHS Employers website. The latest available schedule says that applicants can change their first choice online between
20 April and 23 April. Interviews should take place in May, and applicants should know about the outcome in early June. Junior doctors will be matched to a programme over the following two weeks, and this should be finalised by 18 June. Contracts are to start on 1 August. This timetable leaves doctors just six weeks to arrange housing and family matters if they win a post and need to relocate.

What will happen to unsuccessful applicants? Those without a post can try again by applying in the second round. Neither the dates nor the number of posts have yet been finalised. The second round will run along more traditional lines, with a revised shortlisting and interview process and submission of $\mathrm{CV}$.

Doctors with enough experience could apply for career posts in hospital. These are
Most popular choices of UK medical graduates for specialist training year 1 (ST1), the first level of entry

\begin{tabular}{|c|c|c|c|c|c|c|c|}
\hline \multirow[b]{2}{*}{ Specialty } & \multirow[b]{2}{*}{$\begin{array}{l}\text { No of } \\
\text { posts }\end{array}$} & \multicolumn{2}{|c|}{ No of applications } & \multicolumn{2}{|c|}{ No people shortlisted } & \multicolumn{2}{|c|}{$\begin{array}{c}\% \text { of applications } \\
\text { shortlisted }\end{array}$} \\
\hline & & All & 1st choice & All & 1st choice & All & 1st choice \\
\hline Acute care & 458 & 3523 & 778 & 1235 & 311 & $35 \%$ & $40 \%$ \\
\hline Anaesthesia & 525 & 2538 & 637 & 1184 & 357 & $47 \%$ & $56 \%$ \\
\hline $\begin{array}{l}\text { Core medical } \\
\text { training }\end{array}$ & 1338 & 7781 & 1934 & 2829 & 807 & $36 \%$ & $42 \%$ \\
\hline General practice & 2515 & 15406 & 4241 & 4982 & 3118 & $32 \%$ & $74 \%$ \\
\hline $\begin{array}{l}\text { Obstetrics and } \\
\text { gynaecology }\end{array}$ & 289 & 2023 & 514 & 812 & 219 & $40 \%$ & $43 \%$ \\
\hline Paediatrics & 458 & 2047 & 511 & 927 & 253 & $45 \%$ & $50 \%$ \\
\hline Psychiatry & 594 & 3040 & 713 & 1139 & 311 & $37 \%$ & $44 \%$ \\
\hline $\begin{array}{l}\text { Surgery in } \\
\text { general }\end{array}$ & 850 & 5225 & 1434 & 1672 & 524 & $32 \%$ & $37 \%$ \\
\hline
\end{tabular}

As at 13 April 2007.

Source: www.mtas.nhs.uk/info/ST_2007_1/comp_ratio.html
Keep up to date online

The crisis in UK medical training is complex and is changing day by day. The websites listed below provide useful background information and latest news.

Medical Training Application Service (MTAS)

www.mtas.nhs.uk

- Manage your application

- Check competition tables

- See announcements

Modernising Medical Careers (MMC)

www.mmc.nhs.uk

- Learn about the new training schemes

- View the frequently asked questions

- Find announcements and updates

\section{NHS Employers}

www.nhsemployers.org

- Read latest guidance for applicants, medical

directors, and NHS managers

- Check the most recent timetable

- Find news updates and read the frequently

asked questions

Remedy UK

www.remedyuk.net

- Hear an alternative to the official voices

- Find out about junior doctors' protest plans

- Read background information about the reforms

BMJ

- Read Lynn Eaton's news blog at http://blogs. bmj.com/category/comment/mtas

service delivery posts with no formal specialty training. They are available only in secondary care, and doctors will have to have at least three years' post-registration experience to be eligible for such posts. Those taking this route may find it difficult to re-enter training.

Others may decide to leave the country or the profession. Recruiters from New Zealand and Australia are already stepping up their activity in the UK.

\section{What's the long term effect?}

Junior doctors worry that their generation will become cynical and disillusioned about medicine. Young people may not see medicine as an attractive career option, and the quality of applicants to UK medical schools could decline. The signs are already there. Last week the BMA surveyed 964 junior doctors aged between 22 and 35 . Half did not expect to be working in the NHS within 10 years, and most thought that more health care would be provided by the private sector, with a detrimental effect on patients. Half thought that medicine was no longer a lifelong career. Colleen Shannon is a freelance medical journalist colleenshannonuk@yahoo.co.uk 